\title{
A MENTE ASSOMBRADA DE OLIVER SACKS
}

SACKS, Oliver. A mente assombrada. Trad. Laura Teixeira Motta. São Paulo: Companhia das Letras, 2013, 287 p.

\section{Reginaldo José Horta*}

O delírio épico do personagem Brás Cubas narrado no romance homônimo de Machado de Assis encontra-se entre as páginas mais brilhantes e criativas da nossa literatura. No relato de Machado, o "autor defunto" Brás Cubas, depois de ver-se transformado na Suma Teológica de Santo Tomás, é transportado por um hipopótamo até à origem dos séculos onde, arrebatado por Pandora, vê passar diante dos seus olhos a história do homem e da Terra, num turbilhão de imagens e sons que se lhe configura um "acerbo e curioso espetáculo". Na esteira do finado Brás Cubas, outros personagens igualmente delirantes povoam a literatura mundial - veja-se, para citar apenas alguns exemplos, os devaneios de Hans Castorp, herói de $A$ montanha mágica, de Thomas Mann; os delírios febris de Raskólnikov em Crime e castigo, de Dostoiévski; as alucinações de Peter Kien e seus diálogos inverossímeis com o filósofo Confúcio e com a governanta Therese Krumbholz, em Auto-de-fé, de Canetti; as experiências viscerais e perturbadoras vividas por Antoine Roquentin em suas andanças por Bouville, magistralmente narradas por Sartre em A náusea. Nas vivências desses personagens, os limites entre a realidade e o sonho são tão borrados e intangíveis que terminam por nos causar a impressão de que, mais do que tênues, eles simplesmente não existem. Tal como na arte, será também assim na vida? As alucinações pertencem necessariamente ao campo da loucura ou são parte de nossa experiência do mundo? Qual o limite entre o real e o fantástico, o normal e o patológico, a literatura e a vida?

A propósito, não são poucos os personagens do livro $A$ mente assombrada, do neurologista britânico Oliver Sacks, que parecem ter saído diretamente da pena daqueles autores citados acima. O mais curioso é que, no caso de Sacks, trata-se de personagens/pacientes reais cujos delírios e alucinações são tão ou mais perturbadores e

\footnotetext{
* Mestrado em Filosofia pela Faculdade Jesuíta de Filosofia e Teologia (2015). Professor de Filosofia no Instituto Santo Tomás de Aquino (ISTA) e na Universidade Salgado de Oliveira (UNIVERSO-BH).
} 
fantásticos do que aqueles produzidos pela nossa melhor literatura. Um lançar de olhos sobre algumas das inúmeras histórias narradas por Sacks nesse que foi seu penúltimo livro publicado apenas três anos antes de sua obra derradeira, a autobiografia Sempre em movimento: uma vida (2015) - nos permite reconhecer o misto de curiosidade científica, perspicácia médica e talento literário deste que é também o autor celebrado de clássicos como Tempo de Despertar (1973), O homem que confundiu sua mulher com um chapéu (1985) e Um antropólogo em Marte (1995).

Em A mente assombrada, uma historiadora vê um adolescente deitado no capô do carro, com os pés para o ar, enquanto dirige seu automóvel; em casa, ao olhar-se no espelho, vê seu cabelo erguendo-se quase meio metro acima da cabeça e costuma enxergar letras hebraicas pretas com trajes brancos de balé dançando à sua frente. Outra paciente sente gosto de óleo de máquina quando come chocolate, gosto de aguarrás quando experimenta alface e o cheiro de café se lhe apresenta com um fedor tão horripilante que o marido é obrigado a tomar café apenas no trabalho. Diane G., vítima de alucinações com músicas e conversas, relata ouvir diariamente Bing Crosby e orquestra tocando "White Christmas" num volume tão alto que lhe é impossível ouvir qualquer outra coisa. Alucinações com rostos estranhos, formas geométricas, pautas musicais, cheiros improváveis, cores vibrantes, personagens desconhecidos, cenas e lugares exóticos permeiam os relatos de Sacks no livro, numa exibição espantosa e fascinante da incrível fauna mental que por vezes emerge e vem à tona sem que saibamos ao certo como e por que. O fato é que, segundo Sacks, muitas dessas alucinações são mais comuns do que se imagina e a maior parte delas nada tem a ver com loucura, mas pertencem ao registro das "alucinações corriqueiras", provocadas, na maioria das vezes, pela superativação de circuitos cerebrais responsáveis pela percepção dos sentidos. Verdade que algumas delas, como demonstra o autor, encontram-se diretamente relacionadas a certas doenças, como é o caso do parkinsonismo, da esquizofrenia e da epilepsia, enquanto outras estão ligadas a certos distúrbios associados à percepção, como no caso da síndrome de Charles Bonnet, em que pacientes que perderam a visão vivem imersos num mundo de cores, formas e imagens de fazer inveja a qualquer pintor surrealista.

Ao longo dos quinze capítulos que compõem o livro, Sacks nos conduz às histórias reais de seus inúmeros pacientes, tanto revelando com sensibilidade e raro senso de oportunidade seus dramas pessoais, suas angústias, suas excentricidades quanto fazendo de seus respectivos casos - cada um mais envolvente e curioso do que o outro - matéria de investigação sobre as potencialidades não suficientemente exploradas dos nossos sentidos e 
objeto de reflexão acerca dos eventos extraordinários produzidos pela mente. Na contramão de toda uma tradição médico-psiquiátrica que insiste em ver muitos casos de alucinações como evidência de loucura ou de outros distúrbios mentais graves, como é o caso da esquizofrenia, Sacks mostra como grande parte dos casos de alucinações nada tem a ver com patologia mental, estando antes associados à vivência de emoções extremas, ao uso de psicotrópicos ou mesmo a experiências religiosas como aquelas que William James chamava de "agudas". Nesse ínterim, Sacks chama a atenção para o importante papel desempenhado pelas alucinações nos campos da arte, da religião e da cultura e evoca a autoridade de literatos, filósofos e cientistas para corroborar a tese de que, sem o escape proporcionado pelo delírio e a alucinação, a vida humana não seria apenas mais pobre, simplesmente não seria totalmente humana.

A esse propósito, cumpre destacar aquele que é talvez um dos capítulos mais interessantes e instigantes de todo o livro no qual o autor trata das diversas alucinações provocadas pelo uso de drogas e relata inclusive suas próprias experiências com elas durante a década de 1960. Este capítulo, que se inicia com o que poderíamos chamar de um "elogio da transcendência", revela o modo como o então estudante de neurologia de Oxford encarava estas experiências com drogas, vistas por ele assim como por muitos de sua época tanto como sérias investigações neuroquímicas quanto como atalhos para a "transcendência imediata". Vale, pois, a pena citar literalmente o parágrafo inicial deste capítulo devidamente intitulado "Estados alterados": "o ser humano tem muito em comum com outros animais - as necessidades básicas de se alimentar, beber e dormir, por exemplo -, mas há outras necessidades mentais e desejos emocionais que talvez sejam exclusivamente nossos. Viver apenas o dia presente é insuficiente para um ser humano; precisamos de transcendência, de arroubo, de escape; precisamos de significado, compreensão e explicação (...). Precisamos de esperança, de um senso de futuro. E precisamos de liberdade (ou pelo menos da ilusão de liberdade) para ir além de nós mesmos, seja com telescópios e microscópios e com a nossa sempre florescente tecnologia, seja em estados de espírito que nos permitam viajar para outros mundos, transcender nosso ambiente imediato. Precisamos desse tipo de afastamento tanto quanto de algo que nos absorva na vida" (p.89).

A espantosa erudição de Sacks e sua peculiar capacidade de observação acurada do exótico revela-se em toda a sua riqueza neste capítulo acerca dos "estados alterados". Ali ficamos sabendo de sua verdadeira fascinação pelas alterações mentais causadas pelas drogas, fascinação que o levou a ler tudo o que de mais relevante foi escrito sobre o tema, desde os 
clássicos literários de De Quincey (Confissões de um comedor de ópio), Baudelaire (Paraísos artificiais) e Aldous Huxley (As portas da percepção e Céu e inferno), aos mais técnicos livros e artigos científicos dedicados aos efeitos alucinatórios das drogas, sobretudo as ilícitas. Dentre os relatos mais curiosos desta safra encontram-se aqueles ligados aos testes sobre o LSD realizados na Universidade Columbia nos anos 1960. Sacks relata a "rica cinestesia" que define como "uma mescla de todos os sentidos, de sensações e conceitos" experimentada por um dos sujeitos da pesquisa, Daniel Breslaw, após o uso do LSD. Segundo o relato de Breslaw, reproduzido no livro, quando os efeitos da droga chegavam à sua intensidade máxima, as interações entre os sentidos eram tão frequentes e tão impressionantes que lhe permitiam dizer qual era o cheiro de um si bemol, o som do verde e até o gosto do imperativo categórico - que ele dizia ser "mais ou menos como o [gosto] de vitela". Tanto esta como outras inúmeras e multifacetadas formas de alucinação - espontâneas ou autossugeridas - descritas por Sacks encontram-se sempre associadas aos sentidos, de modo que poderíamos afirmar que eles, os sentidos, mais do que os personagens evocados pelo autor, é que constituem os verdadeiros protagonistas do livro.

Somente o prazer proporcionado pelas incríveis histórias narradas por Sacks já seria motivo suficiente para justificar a leitura deste seu livro. No entanto, mais do que isso, sua leitura nos permite considerar sobre outro ângulo o papel desempenhado pelos sentidos em nossa percepção e compreensão da realidade, constituindo, de certo modo, uma contraposição a toda uma tradição filosófica que, ao menos desde Platão, costuma nutrir uma exagerada desconfiança, se não um verdadeiro ódio, aos sentidos. Além disso, para aqueles interessados nas discussões atuais que dominam o campo fértil da Filosofia da Mente, este como os demais livros de Sacks são de leitura obrigatória. Na esteira de autores igualmente eruditos, criativos e originais como Stephen Jay Gould, Carl Sagan, António Damásio e V.S. Ramachandran (de quem Sacks foi amigo próximo, tendo inclusive assinado a apresentação do maravilhoso livro de Ramachandran, Fantasmas no cérebro), Sacks é um mestre na arte de contar histórias e seu admirável senso literário quase que rivaliza com seu enorme conhecimento científico, conhecimento esse que ele não esconde sob o jargão abstruso e hermético dos médicos, mas que oferece ao leitor com a clareza, a graça e a generosidade que lhe são peculiares.

Por fim, este texto, mais do que uma resenha de A mente assombrada, pretende ser uma pequena homenagem a Oliver Sacks, que nos deixou em agosto deste ano. Como pensamos não haver melhor maneira de homenagear um autor senão lendo seus livros e divulgando suas ideias, queremos recomendar enfaticamente a leitura de suas obras, todas elas 
publicadas no Brasil em primorosas edições da Companhia das Letras. A última delas, como já dissemos, foi sua autobiografia Sempre em movimento, de onde retiramos a definição que se segue, já que pensamos ser ela a que melhor faz justiça ao autor de Tempo de despertar: "acima de tudo, fui um ser com sentidos, um animal pensante, neste maravilhoso planeta e isso, em si, foi um enorme privilégio e uma aventura". 